\title{
Revisiting Students' Reflection in Mathematics Learning: Defining, Facilitating, Analyzing, and Future Directions
}

\author{
Shin-Yi Lee \\ Department of Education, University of Taipei, Taiwan \\ Received November 15, 2020; Revised December 24, 2020; Accepted January 28, 2021
}

\section{Cite This Paper in the following Citation Styles}

(a): [1] Shin-Yi Lee, "Revisiting Students' Reflection in Mathematics Learning: Defining, Facilitating, Analyzing, and Future Directions," Universal Journal of Educational Research, Vol. 9, No. 1, pp. 154 - 160, 2021. DOI: 10.13189/ujer.2021.090117.

(b): Shin-Yi Lee (2021). Revisiting Students' Reflection in Mathematics Learning: Defining, Facilitating, Analyzing, and Future Directions. Universal Journal of Educational Research, 9(1), 154 - 160. DOI: 10.13189/ujer.2021.090117.

Copyright $\mathrm{C} 2021$ by authors, all rights reserved. Authors agree that this article remains permanently open access under the terms of the Creative Commons Attribution License 4.0 International License

\begin{abstract}
Students rarely reflect on mathematics. Reflection requires higher order cognition that has proven difficult to teach. Much of the literature in mathematics learning has highlighted the significance of reflection without, however, offering much enlightenment on the current research status of students' reflection within mathematical situations. In this study, a wide range of academic literature associated with students' reflection within mathematical situations is reviewed. Three important aspects then emerge from the literature review: how to operationally define, individually facilitate, and analyze students' reflection within mathematical situations. Based on the three emerging important aspects, it would be worthwhile for future studies to develop an operational definition of reflection in mathematics learning, to research how students' reflection relates to their cognition and metacognition within mathematical situations, to invent individual reflective strategies in mathematics learning and to investigate the effect of such strategies on their mathematical performance, to devise techniques to analyze students' reflective behaviors within mathematical situations, and to explore the extent to which students' reflection could be promoted in mathematics learning. It is hoped that this article will develop ideas for future practice and research on students' reflection within mathematical situations about students' reflection and the role it plays in mathematics learning.
\end{abstract}

Keywords Communication, Mathematics Education, Problem Solving, Reflection

\section{Introduction}

Reflection plays an essential role in students' mathematics learning [1-4]. Carpenter \& Lehrer [5] identified reflection as one of "five forms of mental activity from which mathematical understanding emerges" (p. 22). Furthermore, studies have indicated that understanding can be enhanced by reflection $[6,7,8]$. Kilpatrick [9] stated that reflection instructional approaches were based on the belief that students learn not only by doing but also by thinking about what they and others do. Despite its importance in mathematics learning, little is known about students' reflection within mathematical situations [10]. Even less is known about the current research status of students' reflection within mathematical situations. Three key aspects emerge from a comprehensive literature review on the topic. These aspects were how to operationally define, individually facilitate, and analyze students' reflection within mathematical situations. With respect to the aspects, the present study is to discuss ideas of reflection and the relationship between reflection and metacognition in mathematics learning, to present activities facilitating students' reflection in mathematics classrooms, and to consider ways to analyze students' reflective behaviors within mathematical situations.

\section{Ideas of Reflection in Mathematics Learning}

In mathematics learning, various ideas of reflection 
have been used based on Dewey [11], Piaget [12], Polya [13], Schön [14] and so on. Dewey [11] indicated that reflection is "the kind of thinking that consists of turning a subject over in the mind and giving it serious and consecutive consideration" (p. 3). Through reflection, previous thoughts are reviewed, experience and learning are connected, and deep learning can take place [11].

Piaget [12] used the notion of reflective abstraction to describe an individual's construction of logico-mathematical structures by his or her personal reflections. Reflective abstraction is critically important to the theory of constructivism [15].

In mathematical problem solving, Polya [13] used the term of "look back" to represent the ideas of reflection $[16,17]$. He claimed that students can consolidate their knowledge and develop their problem solving ability by "looking back at the completed solution, by reconsidering and reexamining the result and the path that led to it" ( $\mathrm{p}$. 14).

In his seminal work on reflection, Schön [14] created the terms "reflection-in-action" and "reflection-on-action". The former enables students to reflect during their learning activity and serves to reshape what they are doing while they are doing it. The latter refers to thinking back on what has been done to develop questions or ideas about past activities. Schön [18] proposed reflection as a means to integrate theory with practice.

While various ideas of reflection have been used in literature on mathematics learning, the concept of reflection is not clear [19-23]. To facilitate theoretical and empirical work on students' reflection in mathematics education, more studies are needed to develop an operational definition of reflection in mathematics learning.

Further literature indicates that reflection is a precondition to promote students' metacognitive development $[20,24]$. When students reflect, they are encouraged to develop their cognitive and metacognitive skills $[16,17,25]$, both of which contribute greatly to their mathematical performance [26,27,28]. Little, however, was known about how reflection relates to cognition or to metacognition [20]. Studies should be undertaken to investigate how students' reflection relates to their cognition or metacognition in mathematics learning.

\section{Activities to Facilitate Students' Reflection}

Literature has indicated that students rarely reflect on mathematics $\quad[10,13,29,30,31,32,33,34]$. Their "consciousness of reflection in mathematical thinking is low" and they have limited strategies to reflect on their mathematical activities [10]. They often "adopt what initially seems like a reasonable approach to a problem and then proceed to follow it without further evaluation of their decision as long as they are able to keep working" [30] (p. 10). "Doing so, they miss an important and instructive phase of the work" [13]. Indeed, to maximize their learning opportunities, students should be encouraged to reflect on their learning progress and outcome during and after their learning processes. As Dewey [11] maintained, reflection must be promoted in students' learning activities.

Reflection requires higher order cognition that has proven difficult to teach [10]. Instruction in other techniques requiring students to reflect may be fruitful. Literature has suggested that communication and problem solving encourage students to reflect [7,35-40]. This section will review how these reflective strategies were implemented in mathematics classrooms and their effects on students' mathematics learning.

\subsection{Communication}

Communication means "participating in social interaction, sharing thoughts with others and listening to others share their ideas" [41] (p. 5). Researchers have described the relationship between communication and reflection $[42,43,44]$. NCTM [44] claimed "reflection and communication are interwined processes in mathematical learning" (p. 61). Carpenter \& Lehrer [43] described the relationship between communication and reflection and stated that "the ability to communicate or articulate one's ideas is an important goal of education, and it also is a benchmark of understanding. ... Articulation requires reflection, and, in fact, articulation can be thought of as a public form of reflection" (p. 22). From sharing their solution methods, students are encouraged to think more deeply about their own ideas in order to explain, clarify or justify them [41]. Hiebert et al. [41] concluded that "students who reflect on what they do and communicate with others about it are in the best position to build useful connections in mathematics" (p. 6).

Some research has investigated how to implement reflection and communication in mathematics classrooms. This section attempts to present different means which have been used to evoke students' reflection through communication and how they influenced students' mathematics learning.

Sfard [45] used the term commognition as a combination of communication and cognition and argued that communication and cognition are two sides of the same coin. "Thinking, when it occurs in a linguistic form, cannot be separated from language" [45] (p. 100). Within the commognitive framework, language is viewed as the main means of intellectual progress, and the acquisition of numerical knowledge is conceptualized as using numerical discourse in an objectified way. Sfard [45] claimed that the perspective of commognition is useful in understanding numerical thinking and abstracting process.

Brink [35] let first-grade students make an arithmetic 
book about sums for next year's first-grade students. The study found that writing the book made students reflect on their own arithmetical knowledge. In the study conducted by Cobb, Boufi, McClain \& Whitenack [36], reflective discourse in which what the students and teacher do subsequently becomes an object of discussion in the class was implemented in a first-grade mathematics classroom. Students' evolving arithmetical conceptions and strategies were investigated in the study. The findings showed that although reflective discourse did not inevitably lead to each child's reflecting, some students did demonstrate mathematical development as classroom discourse progressed.

Powell \& Ramnauth [7] used multiple-entry logs to prompt students' reflection on mathematics text. In multiple-entry logs, students wrote down a mathematics text, their reflection on the text, and sometime later their reflection on previous text or reflection on the same sheet of paper. The mathematics text could be from a textbook, a problem, a discussion, a computer screen, or from any other learning materials. An instructor discussed with students their multiple-entry logs and wrote down responses to their reflection. Powell \& Ramnauth [7] indicated that multiple-entry logs served as vehicles that prompted "learners to reflect on and to deepen their understandings of mathematics" (p. 13).

Lafortune, Daniel, Schleifer \& Pallascio [37] studied philosophical dialogue in an elementary school mathematics classroom and found that students used significantly more higher-order thinking skills than lower-order thinking skills at the end of the study. In their study, students led the dialogue to question peers' ideas on philosophico-mathematical and meta-mathematical questions. The teacher acted as the mediator of the dialogue to help the students justify their opinions and clarify their ideas in the classroom.

\subsection{Problem Solving}

With Dewey's and Schön's work as the foundation for most models and theories of reflection, literature shows that reflection can be precipitated by a perceived problem [38]. In mathematics classrooms, reflection can be promoted by solving mathematical problems either cooperatively or individually.

Cooperative problem solving has been largely suggested to promote students' reflection while solving a mathematical problem $[39,40,46-50]$. In cooperative mathematical problem solving, reflection is stimulated not only by the problem but also by the communication among the students. Since cooperative problem solving allows students to consciously think about what is being done in the solution process through problem solving and communicating, it should facilitate the building of relationships between ideas and increase their mathematical understanding. As suggested by Johnson \&
Johnson [51], cooperative learning developed students' higher quality cognitive strategies.

Artzt \& Armour-Thomas [46] studied the problem solving behaviors of seventh-grade students of varying ability solving a mathematical problem in small groups. They found that "Within the groups, students returned several times to such problem-solving episodes as reading, understanding, exploring, analyzing, planning, implementing, and verifying" (p. 137).

Wheatley [40] implemented problem-centered learning in primary mathematics classrooms in which students were asked to solve mathematical problems in pairs, to develop good arguments to support their solutions, and to present their solutions to the class. In problem-centered learning, teachers' role was not to demonstrate how to solve problems in details but to facilitate their students' construction of mathematical understanding. The results of this study indicated that "elementary students engaged in problem-centered learning develop greater mathematical competence than students taught using the conventional explain-practice method even on standardized tests which feature computation and standard types of problems" (p. 531-532).

When solving problems individually, students may reflect on their learning experience or on their solution process. Literature indicates that students rarely reflect on their solution process while solving problems individually, especially when they get an answer of a problem $[13,16,17,29,30,32,33,34]$. Venezky \& Bregar [52] indicated that "perhaps what grade schoolers need most for improving problem solving abilities is not new and more sophisticated instruction in mathematical concepts, but simply more practice in evaluating solutions and solution plans" (p. 126). "Even fairly good students, when they have obtained the solution of the problem and write down neatly the argument, shut their books and look for something else" [13] (p. 14). More studies need to be conducted to facilitate students' reflection either during or after their individual problem solving process and to investigate the effect of such reflective strategies on their mathematical performance. What follows reviews the limited literature that focuses on feasible ways to promote students' reflection in individual problem solving and their effects on students' mathematical performance.

Polya [13] identifies five questions to prompt students to look back at the completed solution: "Can you check the result? Can you check the argument? Can you derive the result differently? Can you see it at a glance? Can you use the result, or the method, for some other problem?" (p. xvii). Researchers and educators also have identified approaches that can facilitate students' reflection after individually solving mathematical problems and most of them have been centered on Polya's ideas [16,17,29,32,53]. As Silver [54] (cited in Kilpatrick [9]) noted, "many of Polya's heuristic suggestions are...designed to get the problem solver to reflect on his 
or her progress in problem solving and to assess the effectiveness of the procedures being used" [9](p. 10). Based on Polya's ideas of "look back", what follows present ways to promote reflection in individual problem solving and their effects on students' mathematical performance.

Checking the result "can be applied not only to the final result but also to intermediate results" [13] (p. 60). When students obtained an answer to a mathematical problem, the answer should be examined not only for mathematical accuracy and completeness but also for reasonableness and practicality $[13,17]$. Jacobbe [32] investigated the effectiveness of checking the reasonableness of the answer in helping students overcome translation difficulties in algebraic representations. In the study, the students were asked to check their problem solving results by substituting specific values for the problem variables. The findings of the study indicated that the students improved their problem solving performance in algebraic representations.

Multiple solutions contribute greatly to promote students' reflection $[13,17,29,41]$. Through multiple solutions, students are encouraged to solve problems in different ways, to reflect on what they have done during the solution processes, and to build connections among the different solutions. These connections significantly influence students' conceptual understanding [55]. Krulik \& Rudnick [17] claimed that multiple solutions encouraged students to reflect and helped them think about what they have done.

There has been research exploring different means to facilitate students' reflection, among which writing books, reflective discourse, multiple-entry logs, philosophical dialogue, cooperative problem solving, and Polya's look back strategies have been discussed in the above section. Little, however, has been done to develop individual reflective strategies in mathematics learning and to investigate the effect of such strategies on their mathematical performance. The literature on analysis of students' reflective behaviors will be presented next.

\section{Analysis of Students' Reflective Behaviors}

Investigators usually determine existence or level of students' use of reflection based on the context of their verbal activities and actions. Tape recording and verbatim transcriptions of interviews, dialogue, discussion or classroom discourse are usually used to analyze students' reflective behaviors $[36,37,46,49]$. In mathematical problem solving, think-aloud techniques were often used to analyze students' reflective behaviors while solving mathematical problems. In this section, several coding schemes using think-aloud techniques to analyze students' reflective behaviors while solving mathematical problems will be considered. Then, utilization of questionnaires will be discussed.

\subsection{Coding Schemes}

In mathematical problem solving, Polya [13] used the term of "look back" to represent the ideas of reflection $[16,17]$. Schoen \& Oehmke [56] developed a coding scheme for analyzing students' ability to look back when a problem is solved. The scheme was developed to analyze individual think-aloud protocols and "consisted of student moves after a tentative solution was reached" ( $p$. 221). The results indicated that the students rarely looked back during their think-aloud interviews. What follows is a brief description of the scheme.

Many students stopped as soon as they had an answer and were given a score of 0 for step 4 [looking back]. Briefly, a score of 1 was assigned if some uncertainty was expressed but no systematic check was made, a score of 2 was assigned if a check was attempted but was either incorrect or incomplete, and a score of 3 was assigned if a valid check of the computation, conditions, or reasonableness of the solution was carried out. (p. 221)

With the definition of "examination of what was done or learned previously" of "look back," Lee [57] developed a linguistic approach to analyze students" "look back" strategies when they solved problems in multiple solution methods. A coding scheme was developed to identify key utterances which themselves could suggest "examination of what was done or learned previously" during the course of mathematical problem solving. For instance, a student said, "I miscalculated right here." The word "miscalculated" was regarded as an indication of "look back" because it suggested that the student went back to check a prior calculation. It should be noted that indications of "look back" need not be limited to those identified by the study because of the variety of words or phrases subjects might use to express their thoughts.

Furthermore, Lee [57] categorized all of the indications of "look back" identified in the students" "think aloud" protocols into four categories based on their function in the student's problem solving in multiple solution methods. The four categories were "recall", "review", "check", and "compare." What follows presented the four categories.

An indication of "look back" was categorized as "recall" if the student tried to look back at past experience that he or she learned before solving the problem. An indication of "look back" was categorized as "review" if the student tried to look back at a portion of a previous solution process he or she just made during the course of problem solving. An indication of "look back" was categorized as "check" if the student tried to verify the outcome of a part of a solution process. Finally, an indication of "look back" was categorized as "compare" if the student tried to compare a latter solution approach or result with a former one. 
The results indicated that the students who looked back more frequently tended to perform better in multiple solution methods in the problems. Moreover, the students tended to review and to compare more frequently than to recall or to check on the problems during their problem solving processes in multiple solution methods.

\subsection{Questionnaires}

While most studies coded transcriptions of students' verbal activities and actions to analyze their reflective behaviors, several studies used questionnaires to assess students' use of reflection in mathematics learning. For example, to determine the extent to which the students reported the use of reflection when receiving mathematics instruction promoting reflection, Zhang, Zhao \& Yang [10] developed a questionnaire with four scales of frequency of reflection: reflect when asked, reflect occasionally, reflect voluntarily, and reflect very often. The results indicated that although more students reflected after the instruction, most students still didn't reflect. For those who didn't reflect, their reasons for not reflecting were lack of motivation and lack of reflective strategies.

\section{Future Directions}

Reflection is usually neglected by students when learning mathematics. Little is known about how it should be defined operationally, facilitated individually, and analyzed in mathematics learning. The primary purpose of this paper has been to draw attention to these three important aspects of students' reflection within mathematical situations. What follows are the directions for future mathematics education practice and research with respect to the above three aspects. It would be worthwhile for future studies to develop an operational definition of reflection in mathematics learning, to research how students' reflection relates to their cognition and metacognition within mathematical situations, to invent individual reflective strategies in mathematics learning and to investigate the effect of such strategies on their mathematical performance, to devise techniques to analyze students' reflective behaviors within mathematical situations, and to explore the extent to which students' reflection could be promoted in mathematics learning. It is hoped that this article will develop ideas about students' reflection and the role it plays in mathematics learning.

\section{REFERENCES}

[1] Cifarelli, V., Sheets, C., "Problem posing and problem solving: a dynamic connection," School Science and
Mathematics, vol. 109, no. 5, pp. 245-246, 2009.

[2] Freudenthal, H., "Revisiting mathematics education," KAP, 1994.

[3] McGee, D., Brewer, M., Hodgson, T., Richardson, P., Gonulates, F., Weinel,, R. A., "Districtwide Study of Automaticity When Included in Concept-Based Elementary School Mathematics Instruction," School Science \& Mathematics, vol. 117, no. 6, pp. 259-268, 2017.

[4] Prediger, S., "Intercultural perspectives on mathematics learning- Developing a theoretical framework," International Journal of Science and Mathematics Education, vol. 2, pp. 377-406, 2004.

[5] Carpenter, T. P., Lehrer, R., "Planning curriculum in mathematics," 2001.

[6] Duckworth, E., "The having of wonderful ideas and other essays on teaching and learning," TCP, 1996.

[7] Powell, A., Ramnauth, M., "Beyond questions and answers: Prompting reflections and deepening understandings of mathematics using multiple-entry logs," For the Learning of Mathematics, vol. 12, no. 2, pp. 12-18, 1992.

[8] Wiggins, G., McTighe, J., "Understanding by Design," ASCD, 1998.

[9] Kilpatrick, J., "A retrospective account of the past 25 years of research on teaching mathematical problem solving," in Teaching and Learning Mathematical Problem Solving: Multiple Research Perspectives edited by Silver, E. A., LEA, 1985, pp. 1-15.

[10] Zhang, D. Q., Zhao, H. Y., Yang, H., "Fostering mathematical reflective abilities through high school teaching activities," Education China, vol. 4, no. 4, pp. 541$557,2009$.

[11] Dewey, J., "How we think: A restatement of the relation of the reflective thinking to the education process," DCH, 1933.

[12] Piaget, J., "The principles of genetic epistemology," Routledge \& Kegan Paul, 1972.

[13] Polya, G., "How to solve it. Princeton," PUP, 1973.

[14] Schön, D., "The reflective practitioner," BB, 1983.

[15] von Glasersfeld, E., "The construction of knowledge," IP, 1987.

[16] Kersh, M., McDonald, J., "How do I solve thee? Let me count the ways," Arithmetic Teacher, vol. 39, no. 2, pp. 3841, 1991.

[17] Krulik, S., Rudnick, J. A., "Reflect ...for problem solving and reasoning," The Arithmetic Teacher, vol. 41, no. 6, pp. 334-338, 1994.

[18] Schön, D., "Educating the reflective practitioner," JB, 1987.

[19] Boud, D., Walker, D., "Promoting reflection in professional course: The challenge of context," Studies in Higher Education, vol. 23, no. 2, pp. 191-206, 1998.

[20] Desautel, D., "Becoming a thinking thinker: Metacognition, self-reflection, and classroom practice," Teachers College Record, vol. 111, no. 8, pp. 1997-2020, 2009. 
[21] Harrison, M., Short, C., Roberts, C., "Reflecting on reflective learning: The case of geography, earth and environmental sciences," Journal of Geography in Higher Educations, vol. 27, no. 2, pp. 133, 2003.

[22] Husu, J., Toom, A., Patrikainen, S., "Guided reflection as a means to demonstrate and develop student teacher's reflective competencies," Reflective Practice, vol. 9, no. 1, pp. 37-51, 2008.

[23] Rodgers, C., "Defining reflection: Another look at John Dewey and reflective thinking," Teachers College Record, vol. 104, no. 4, pp. 842-866, 2002.

[24] Schunk, D. H., Zimmerman, B. J., "Social origins of self-regulatory competence," Educational Psychologist, vol. 32, pp. 195-208, 1997.

[25] Corden, R., "Developing Reflective Writers in Primary Schools: Findings from partnership research," Educational Review, vol. 54, no. 3, pp. 2495-276, 2002.

[26] Mayer, R. E., "Cognitive, metacognitive, and motivational aspects of problem solving," Instructional Science, vol. 26, pp. 49-63, 1998.

[27] Schoenfeld, A. H., "Mathematical Problem Solving," AP, 1985.

[28] van Velzen, J. H., "Eleventh-grade high school students' accounts of mathematical metacognitive knowledge: Explicitness and Systematicity," International Journal of Science and Mathematics Education, vol. 14, pp. 319-333, 2016.

[29] Cai, J., Brook, M., "Looking back in problem solving," Mathematics Teaching, vol. 196, pp. 42-45, 2006.

[30] Charles, R. I., Lester, F., O’Daffer, P., "How to evaluate progress in problem solving," Reston, National Council of Teachers of Mathematics, 1987.

[31] Gonzales, N. A., "Problem posing: A neglected component in mathematics courses for prospective elementary and middle school teachers," School Science and Mathematics, vol. 94, no. 2, pp. 78-84, 1994.

[32] Jacobbe, T., "Using Polya to overcome translation difficulties," Mathematics Teacher, vol. 101, no. 5, pp. 390 393, 2007

[33] Sowder, L., "The looking-back step in problem solving," The Arithmetic Teacher, vol. 79, pp. 511-513, 1986.

[34] Taback, S., "The wonder and creativity in "looking-back" at problem solutions," The Arithmetic Teacher, pp. 429-435, 1988.

[35] Brink, J. J. D., "Children as arithmetic book authors," For the Learning of Mathematics, vol. 7, no. 2, pp. 44-47, 1987.

[36] Cobb, P., Boufi, A., Clain, M., Whitenack, J., "Reflective discourse and collective reflection," Journal for Research in Mathematics Education, vol. 28, pp. 258-277, 1997.

[37] Lafortune, L., Daniel, M. F., Schleifer, M., Pallascio, R., "Philosophical reflection and cooperative practices in an elementary school mathematics classroom," Canadian Journal of Education, vol. 24, no. 4, pp. 426-440, 1999.

[38] Rogers, R. R., "Reflection in higher education: A concept analysis," Innovative Higher Education, vol. 26, no. 1, pp. 37-57, 2001

[39] Wheatley, G., "Constructivist perspectives on science and mathematics learning," Science Education, vol. 75, no. 1, pp. 9-21, 1991.

[40] Wheatley, G., "The role of reflection in mathematics learning," Educational Studies in Mathematics, vol. 23, pp. 529-541, 1992.

[41] Hiebert, J., Carpenter, T. P., Fennema, E., Fuson, K. C., Wearne, D., Murray, H., "Making sense: Teaching and learning mathematics with understanding," Heinemann, 1997.

[42] Adu-Gyamfi, K., Bosse, M. J., Faulconer, J., "Assessing understanding through reading and writing in mathematics," International Journal for Mathematics Teaching and Learning, 2010.

[43] Carpenter, T. P., Lehrer, R., "Teaching and learning mathematics with understanding," in Mathematics Classrooms that Promote Understanding edited by Fennema, E., Romberg, T. A., LEA, 1999, pp. 19-32.

[44] National Council of Teachers of Mathematics, "Principles and standards for school mathematics," 2000

[45] Sfard, A., "Thinking as communicating: Human Development, the Growth of Discourses, and Mathematizing," New York, CUP, 2008, pp. 100.

[46] Artzt, F., Armour-Thomas, E., "Development of a cognitive-metacognitive framework for protocol analysis of mathematical problem solving in small groups," Cognition and Instruction, vol. 9, no. 2, pp. 137-175, 1992.

[47] Berry, J., Sharp, J., "Developing student-centred learning in mathematics through cooperation, reflection and discussion," Teaching in Higher Education, vol. 4, no. 1, pp. $27-41,1999$

[48] Elbers, E., "Classroom interaction as reflection: Learning and teaching mathematics in a community of inquiry," Educational Studies in Mathematics, vol. 54, pp. 77-99, 2003.

[49] Hershkowitz, R., Schwarz, B., "Reflective processes in a mathematics classroom with a rich learning environment," Cognition and Instruction, vol. 17, no. 1, pp. 65-91, 1999.

[50] Wistedt, I., "Reflection, communication, and learning mathematics: A case study," Learning and Instruction, vol. 4, pp. 123-138, 1994.

[51] Johnson, W., Johnson, T., "Learning together and alone: Cooperative, competitive and individualistic learning," $\mathrm{PH}$, 1987.

[52] Venezky, R. L., Bregar, W. S., "Different levels of ability in solving mathematical word problems," Journal of Mathematical Behavior, vol. 7, pp. 111-134, 1988.

[53] Schoenfeld, A. H., "Teaching problem-solving skills," American Mathematical Monthly, vol. 87, no. 10, pp. 794 $805,1980$.

[54] Silver, E. A., Lester, F. K., Garofalo, J., "Knowledge organization and mathematical problem solving," in Mathematical Problem Solving: Issues in Research, TFIP, 1982. 
[55] Hiebert, J., Carpenter, T. P., "Learning and teaching with understanding," in Mathematics Teaching and Learning edited by Grouws, D., MEDAL, 1992, pp. 65-97.

[56] Schoen, H. L., Oehmke, T., National Council of Teachers of Mathematics, "A new approach to the measurement of problem solving skills," in Problem Solving in School Mathematics: 1980 Yearbook of the National Council of
Teachers of Mathematics edited by Krulik, S., Reys, R. E., 1980, pp. 216-227.

[57] Lee, S. Y., "Students' use of "look back" strategies in multiple solution methods," International Journal of Science and Mathematics Education, vol. 14, no. 4, pp. 701-717, 2016. 